\title{
Effects of Particle Size, Helium Gas Pressure and Microparticle Dose on the Plasma Concentration of Indomethacin after Bombardment of Indomethacin-Loaded Poly-L-Lactic Acid Microspheres Using a Helios ${ }^{\mathrm{TM}}$ Gun System
}

\author{
Masaki Uchida, ${ }^{a}$ Hideshi Natsume, ${ }^{a, b}$ Daisuke Kobayashi, ${ }^{a}$ Kenji Sugibayashi, ${ }^{a, b}$ and \\ Yasunori MORIMOTO $*, a, b$ \\ ${ }^{a}$ Faculty of Pharmaceutical Sciences, Josai University; and ${ }^{b}$ Research Institute of TTS Technology; 1-1 Keyakidai, \\ Sakado, Saitama 350-0295, Japan. Received November 15, 2001; accepted February 6, 2002
}

We investigated the effects of the particle size of indomethacin-loaded poly-L-lactic acid microspheres (IDMloaded PLA MS), the helium pressure used to accelerate the particles, and the bombardment dose of PLA MS on the plasma concentration of IDM after bombarding with IDM-loaded PLA MS of different particle size ranges, $20-38,44-53$ and $75-100 \mu \mathrm{m}$, the abdomen of hairless rats using the Helios ${ }^{\mathrm{TM}}$ gene gun system (Helios ${ }^{\mathrm{TM}}$ gun $^{\mathrm{T}}$ system). Using larger particles and a higher helium pressure, produced an increase in the plasma IDM concentration and the area under the plasma concentration-time curve $(A U C)$ and resultant $F$ (relative bioavailability with respect to intracutaneous injection) of IDM increased by an amount depending on the particle size and helium pressure. Although a reduction in the bombardment dose led to a decrease in $C_{\max }$ and $A U C, F$ increased on decreasing the bombardment dose. In addition, a more efficient $F$ was obtained after bombarding with IDMloaded PLA MS of 75-100 $\mu \mathrm{m}$ in diameter at each low dose in different sites of the abdomen compared with that after bolus bombardment with a high dose (dose equivalent). These results suggest that the bombardment injection of drug-loaded microspheres by the Helios ${ }^{\text {TM }}$ gun system is a very useful tool for delivering a variety of drugs in powder form into the skin and systemic circulation.

Key words microparticulate bombardment system; Helios ${ }^{\mathrm{TM}}$ gene gun system; microparticles

Recently, a microparticulate bombardment system has been investigated for the painless delivery of powdered drug through the stratum corneum to the epidermal-dermal interface using a high velocity supersonic flow of helium gas to accelerate the particles. ${ }^{1)}$ One of the most attractive advantages of this approach is that the stratum corneum does not act as a rate-limiting barrier to drug penetration into the skin. ${ }^{2)}$ Several studies have shown successful local and systemic delivery of drugs, such as peptides, hormones, and vaccines, in animal models using a powder bombardment system, PowderJect. ${ }^{3-6)}$ We have also reported that the He$\operatorname{lios}^{\mathrm{TM}}$ gene gun system (Helios ${ }^{\mathrm{TM}}$ gun system) is a very useful tool for delivering a variety of drugs into the skin as well as introducing DNA and RNA into cells. ${ }^{7)}$ Although DNAand RNA-coated gold and tungsten microparticles $(1-3 \mu \mathrm{m}$ in diameter and about $19 \mathrm{~g} / \mathrm{cm}^{3}$ in density) loaded into a cartridge container of the Helios ${ }^{\mathrm{TM}}$ gun system have been generally used for delivery into cells, indomethacin-loaded poly-L-lactic acid microspheres (IDM-loaded PLA MS) of different size ranges $(20-38,44-53$ and $75-100 \mu \mathrm{m}$, about $1.2 \mathrm{~g} / \mathrm{cm}^{3}$ in density) have been introduced quantitatively into hairless rat skin using the Helios ${ }^{\mathrm{TM}}$ gun system equipped with a novel cartridge container and membrane that ruptures at a helium pressure of 100, 200 and $300 \mathrm{psi}$ $(1 \mathrm{psi}=6890 \mathrm{~Pa}){ }^{7)}$ Introduction of IDM-loaded PLA MS into the skin depended on the particle size and helium pressure, in that bombardment with the largest particles of diameter 75$100 \mu \mathrm{m}$ at a pressure of $300 \mathrm{psi}$ resulted in the highest amounts of IDM being introduced into the skin. In addition, the efficiency of IDM introduction after discrete bombardment with smaller amounts of microspheres of different sites of the abdomen of hairless rats increased significantly compared with that after a single bombardment with larger amounts of microspheres. However, it is necessary to evaluate the systemic availability of IDM introduced into the skin by the Helios ${ }^{\mathrm{TM}}$ gun system.

In the present study, we carried out a pharmacokinetic analysis to investigate the effects of particle size and bombardment dose of IDM-loaded PLA MS, and the helium pressure used to accelerate PLA MS on the plasma concentration of IDM after bombardment with IDM-loaded PLA MS using the Helios ${ }^{\mathrm{TM}}$ gun system in hairless rats. We also evaluated the plasma IDM concentration after discrete bombardment.

\section{MATERIALS AND METHODS}

Materials Indomethacin was purchased from Wako Pure Chemical Industries, Ltd. (Osaka, Japan). Poly-L-lactic acid (Molecular weight $c a$. 10000) was obtained from Nacalai Tesque, Inc. (Kyoto, Japan). A polyvinyl chloride film (thickness $10 \mu \mathrm{m}$ ), used as the rupture membrane, was purchased from Hitachi Chemical Filtec Inc. (Tokyo, Japan). All other chemicals were of reagent grade.

Animals Male WBN/ILA-Ht hairless rats (weight 240$290 \mathrm{~g}$ ) were supplied by the Life Science Research Center of Josai University (Saitama, Japan). The experiments were performed in accordance with the guidelines for animal use in the Life Science Research Center, Josai University.

Preparation of IDM-Loaded PLA MS IDM-loaded PLA MS were prepared as described previously. ${ }^{7)}$ Briefly, $100 \mathrm{mg}$ IDM and $300 \mathrm{mg}$ PLA were dissolved in $3 \mathrm{ml}$ dichloromethane $\left(\mathrm{CH}_{2} \mathrm{Cl}_{2}\right)$. This solution was then added to $150 \mathrm{ml} 0.5 \%$ polyvinyl alcohol aqueous solution while stirring at $2000 \mathrm{rpm}$ for $25 \mathrm{~min}$ at room temperature. Thereafter, the mixture was continuously stirred at $1000 \mathrm{rpm}$ for $5 \mathrm{~h}$ at 
$37^{\circ} \mathrm{C}$ to evaporate $\mathrm{CH}_{2} \mathrm{Cl}_{2}$. The hardened IDM-loaded PLA MS were washed with distilled water then divided into the required particle size ranges using stainless-steel mesh sieves (20-38, 44-53 and $75-100 \mu \mathrm{m}$ in diameter). The IDM content of PLA MS with a diameter of $20-38,44-53$ and $75-100 \mu \mathrm{m}$ was $10.4,18.8$ and $22.2 \%$, respectively.

Particle Bombardment of the Skin with IDM-Loaded PLA MS Using the Helios ${ }^{\text {TM }}$ Gun System After anesthetizing (urethane $1 \mathrm{mg} / \mathrm{kg}$ i.p.) hairless rats, $0.5,1.0$ and $3.0 \mathrm{mg}$ of IDM-loaded PLA MS (20-38, 44-53 and 75$100 \mu \mathrm{m}$ in diameter) were transferred to the novel cartridge container fitted with a polyvinyl chloride film (thickness $10 \mu \mathrm{m})$ as a rupture membrane. The cartridge containers were placed in a cartridge holder with twelve holes. IDMloaded PLA MS in the cartridge container was accelerated by the high velocity helium gas in the Helios ${ }^{\mathrm{TM}}$ gun system to bombard the shaved abdominal skin. ${ }^{7}$ The helium pressures used were 100, 200 and 300 psi, respectively ( 1 psi= $6890 \mathrm{~Pa})$.

Discrete Particle Bombardment with IDM-Loaded PLA MS of Different Sites of the Skin Using the Helios ${ }^{\text {TM }}$ Gun System After anesthetizing (urethane $1 \mathrm{mg} / \mathrm{kg}$ i.p.) hairless rats, $1.0 \mathrm{mg}$ IDM-loaded PLA MS of $75-100 \mu \mathrm{m}$ in diameter was transferred to each cartridge container. The IDM-loaded PLA MS in the cartridge container in a cartridge holder was then used to bombard the shaved abdominal skin at three different sites to deliver total amounts of $3.0 \mathrm{mg}$. The helium pressure used was $300 \mathrm{psi}$.

Intracutaneous (i.c.) Injection of IDM Solution After anesthetizing (urethane $1 \mathrm{mg} / \mathrm{kg}$ i.p.) hairless rats, $25 \mu \mathrm{l}$ IDM $(100 \mu \mathrm{g} / \mathrm{kg}$ in dose) in phosphate-buffered saline (PBS, $\mathrm{pH}$ 7.4) was injected intracutaneously into the abdomen.

Determination of Plasma Concentration of IDM Blood samples were collected from the jugular vein via a heparinized syringe at predetermined times and centrifuged at $13600 \mathrm{rpm}(18000 \times \boldsymbol{g})$ for $5 \mathrm{~min}$ at $4{ }^{\circ} \mathrm{C}$ to obtain plasma. Plasma samples were mixed with acetonitrile containing $n$ hexyl $p$-hydroxybenzoate as an internal standard $(1: 2)$ and then centrifuged at $13600 \mathrm{rpm}(18000 \times \boldsymbol{g})$ for $5 \mathrm{~min}$ at $4{ }^{\circ} \mathrm{C}$. The obtained supernatants were stored in a refrigerator until analysis. IDM concentrations were determined by HPLC as described previously. ${ }^{7)}$

Data Analysis Plasma data were analyzed by a non-linear least squares regression program (Algorithm: Damping Gauss-Newton method). ${ }^{8)}$ The $C_{\max }$ and $T_{\max }$ values were obtained from the IDM concentration-time curves and the area under the plasma concentration-time curve $(A U C)$ were calculated by the trapezoidal rule.

$F_{0-24 \mathrm{~h}}$ (relative bioavailability with respect to i.c. injection) was calculated as follows:

$$
F_{0-24 \mathrm{~h}}=\frac{A U C_{\text {bombard } 0-24 \mathrm{~h}} / \text { Dose }_{\text {bombard }}}{A U C_{\text {i.c. } 0-24 \mathrm{~h}} / \text { Dose }_{\text {i.c. }}} \times 100
$$

where $A U C_{\text {bombard } 0-24 \mathrm{~h}}$ and $A U C_{\text {i.c. } 0-24 \mathrm{~h}}$ are the areas under the plasma concentration of IDM versus time $(0-24 \mathrm{~h})$ curves after particle bombardment and i.c. injection, respectively. Dose $_{\text {bombard }}$ and Dose $e_{\text {i.c. }}$ are the IDM dose $(\mu \mathrm{g} / \mathrm{kg})$ in the particle bombardment and i.c. injection, respectively.

The absorption rate constant, $k_{\mathrm{a}}$, and absorption profile of IDM after bombardment was obtained by applying a deconvolution method to the bombardment and i.c. data. The elim- ination kinetic parameters for the i.c. injection were almost the same as those for the i.v. injection. The $k_{12}, k_{21}, k_{\mathrm{el}}, V_{\mathrm{ss}}$ and total CL obtained from the i.c. data were 1.21, 0.530 and $0.0674 \mathrm{~h}^{-1}$, and $190.0 \mathrm{ml} / \mathrm{kg}$ and $3.91 \mathrm{ml} / \mathrm{h} / \mathrm{kg}$, respectively. The maximum absorption rate (MAR) was obtained from the slope of the absorption profile. The slope of the profile was calculated for time points at $10 \mathrm{~min}$ intervals.

Statistical analyses were performed using Student's $t$-test.

\section{RESULTS AND DISCUSSION}

Effects of Particle Size, Helium Pressure and Bombardment Dose on the Plasma Concentration of IDM Figure 1 shows typical plasma concentration-time curves of IDM after bombarding the abdomen of hairless rats with IDMloaded PLA MS using the Helios ${ }^{\mathrm{TM}}$ gun system under various conditions. Table 1 summarizes the IDM pharmacokinetic parameters obtained. The efficiency of IDM introduction (\% introduction) into the skin obtained previously is also listed. ${ }^{7)}$ The skin was excised immediately after bombardment of IDM-loaded PLA MS under different conditions and, thereafter, the amounts of IDM introduced into the skin were determined following extraction.

The percentage introduction of IDM into the skin was calculated as follows:

$$
\% \text { introduction }=\frac{\text { amount of IDM into the skin }}{\text { loading dose of IDM }} \times 100
$$

where the loading dose of IDM is the IDM content of the PLA MS in the cartridge container. The recovery of IDM from skin lysate was almost complete $(99.8 \pm 0.66 \%, n=6)$.

When IDM-loaded PLA MS with different particle size ranges, at a dose of $1.0 \mathrm{mg}$, were bombarded at a helium pressure of $300 \mathrm{psi}$, the plasma concentration of IDM increased with increasing particle size (Fig. 1a). The $C_{\max }$ and $A U C_{0-24 \mathrm{~h}}$ values increased in relation to the particle size (Table 1). The same trend was observed at helium pressures of 100 and 200 psi. The $F_{0-24 \mathrm{~h}}$ was also dependent on the particle size, although the $C_{\max }$ and $A U C_{0-24 \mathrm{~h}}$ were affected by the MS drug content. As shown in Fig. $1 \mathrm{~b}$ and Table 1 , the plasma concentration of IDM after bombardment with IDMloaded PLA MS of $75-100 \mu \mathrm{m}$ in diameter, at the same dose of $1.0 \mathrm{mg}$, increased with increasing helium pressure. The $C_{\max }, A U C_{0-24 \mathrm{~h}}$ and $F_{0-24 \mathrm{~h}}$ values also increased in relation to the helium pressure. A helium pressure-dependence of $F_{0-24 \mathrm{~h}}$ was observed at all particle size ranges, in that a higher helium pressure produced a higher efficiency. The particle size and helium pressure were also found to correlate with the $\%$ introduction into the skin (Table 1). Consequently, good relationships between the $F_{0-24 \mathrm{~h}}$ and the $\%$ introduction, at each particle sizes for the helium pressure, were observed. Burkoth et al. have suggested that the release of drugs, introduced via the skin by the particle bombardment system, correlated well with results in vivo. ${ }^{3)}$ It seems, therefore, that the IDM plasma concentration depends on the amount of introduction, in that the $F_{0-24 \mathrm{~h}}$ is influenced by helium pressure used.

The absorption rate constant, $k_{\mathrm{a}}$, was almost the same at a dose of $1.0 \mathrm{mg}$ at the same helium pressure and particle size ranges, although the $k_{\mathrm{a}} \mathrm{s}$ obtained at a helium pressure of 100 psi at each particle size range was different from those 



Fig. 1. Plasma Concentration of IDM after Bombardment with IDM-Loaded PLA MS Using the Helios ${ }^{\mathrm{TM}}$ Gun System under Various Conditions

a) Effect of particle size, b) effect of helium pressure, c) effect of bombardment dose. Needle injection: $\bullet$, i.c. injection $(100 \mu \mathrm{g} / \mathrm{kg})$. Particle bombardment: $\nabla, 20-38 \mu \mathrm{m}$, $1.0 \mathrm{mg}, 300 \mathrm{psi} ; \diamond, 44-53 \mu \mathrm{m}, 1.0 \mathrm{mg}, 300 \mathrm{psi} ; \square, 75-100 \mu \mathrm{m}, 1.0 \mathrm{mg}, 300 \mathrm{psi} ; \bigcirc, 75-100 \mu \mathrm{m}, 1.0 \mathrm{mg}, 100 \mathrm{psi} ; \triangle, 75-100 \mu \mathrm{m}, 1.0 \mathrm{mg}, 200 \mathrm{psi} ; \boldsymbol{\Delta}, 75-100 \mu \mathrm{m}, 0.5 \mathrm{mg}$, $300 \mathrm{psi} ; \diamond, 75-100 \mu \mathrm{m}, 3.0 \mathrm{mg}, 300 \mathrm{psi}$. Each data point represents the mean and the standard error $(n=3-6)$.

Table 1. Percentage Introduction and Pharmacokinetic Parameters of IDM after Bombardment with IDM-Loaded PLA MS Using the Helios ${ }^{\mathrm{TM}}$ Gun System under Various Conditions

\begin{tabular}{|c|c|c|c|c|c|c|c|c|}
\hline & & $\%$ introduction & $\begin{array}{c}C_{\max } \\
(\mu \mathrm{g} / \mathrm{ml})\end{array}$ & $\begin{array}{l}T_{\max } \\
\text { (h) }\end{array}$ & $\begin{array}{l}A U C_{0-24 \mathrm{~h}} \\
(\mu \mathrm{g} \cdot \mathrm{h} / \mathrm{ml})\end{array}$ & $\begin{array}{c}k_{\mathrm{a}} \\
(\mathrm{l} / \mathrm{h})\end{array}$ & $\begin{array}{l}\text { MAR } \\
(\mu \mathrm{g} / \mathrm{h})\end{array}$ & $\begin{array}{c}F_{0-24 \mathrm{~h}^{a}} \\
(\%)\end{array}$ \\
\hline $\begin{array}{l}\text { i.c. } \\
\text { IDM solution } \\
(100 \mu \mathrm{g} / \mathrm{kg})\end{array}$ & & - & $1.42 \pm 0.05$ & $0.17 \pm 0.00$ & $10.2 \pm 0.38$ & - & - & - \\
\hline $\begin{array}{l}20-38 \mu \mathrm{m}^{b)} \\
1.0 \mathrm{mg} \mathrm{MS} / \mathrm{rat} \\
(104 \mu \mathrm{g} \mathrm{IDM} / \text { rat })\end{array}$ & $\begin{array}{l}100 \mathrm{psi} \\
200 \mathrm{psi} \\
300 \mathrm{psi}\end{array}$ & $\begin{array}{l}20.7 \pm 3.00 \\
24.7 \pm 4.11 \\
29.2 \pm 4.20\end{array}$ & $\begin{array}{l}0.05 \pm 0.01 \\
0.21 \pm 0.03 \\
0.28 \pm 0.05\end{array}$ & $\begin{array}{l}12.0 \pm 0.00 \\
1.67 \pm 0.33 \\
5.33 \pm 3.33\end{array}$ & $\begin{array}{l}0.90 \pm 0.10 \\
3.58 \pm 0.29 \\
5.49 \pm 0.87\end{array}$ & $\begin{array}{l}0.171 \\
0.476 \\
0.473\end{array}$ & $\begin{array}{l}1.45 \\
15.2 \\
16.0\end{array}$ & $\begin{array}{l}2.20 \\
9.04 \\
13.7\end{array}$ \\
\hline $\begin{array}{l}44-53 \mu \mathrm{m}^{b)} \\
1.0 \mathrm{mg} \mathrm{MS} / \mathrm{rat} \\
(188 \mu \mathrm{g} \mathrm{IDM} / \mathrm{rat})\end{array}$ & $\begin{array}{l}100 \mathrm{psi} \\
200 \mathrm{psi} \\
300 \mathrm{psi}\end{array}$ & $\begin{array}{l}19.7 \pm 2.65 \\
25.5 \pm 4.61 \\
30.1 \pm 6.67\end{array}$ & $\begin{array}{l}0.13 \pm 0.02 \\
0.47 \pm 0.06 \\
0.53 \pm 0.07\end{array}$ & $\begin{array}{l}6.00 \pm 1.54 \\
4.00 \pm 1.41 \\
2.67 \pm 0.67\end{array}$ & $\begin{array}{l}2.41 \pm 0.34 \\
8.77 \pm 1.32 \\
9.97 \pm 1.66\end{array}$ & $\begin{array}{l}0.271 \\
0.496 \\
0.499\end{array}$ & $\begin{array}{l}5.41 \\
27.3 \\
37.4\end{array}$ & $\begin{array}{l}3.18 \\
11.7 \\
13.7\end{array}$ \\
\hline $\begin{array}{l}75-100 \mu \mathrm{m} \\
0.5 \mathrm{mg} \mathrm{MS} / \mathrm{rat} \\
(111 \mu \mathrm{g} \mathrm{IDM} / \mathrm{rat})\end{array}$ & $300 \mathrm{psi}$ & $35.6 \pm 4.16$ & $0.81 \pm 0.11$ & $2.67 \pm 0.67$ & $12.5 \pm 0.78$ & 0.645 & 53.8 & 25.0 \\
\hline $\begin{array}{l}75-100 \mu \mathrm{m}^{b)} \\
1.0 \mathrm{mg} \mathrm{MS} / \mathrm{rat} \\
(222 \mu \mathrm{g} \mathrm{IDM} / \mathrm{rat})\end{array}$ & $\begin{array}{l}100 \mathrm{psi} \\
200 \mathrm{psi} \\
300 \mathrm{psi}\end{array}$ & $\begin{array}{l}30.4 \pm 6.00 \\
33.8 \pm 5.17 \\
39.6 \pm 3.04\end{array}$ & $\begin{array}{l}0.39 \pm 0.17 \\
0.80 \pm 0.04 \\
1.21 \pm 0.12\end{array}$ & $\begin{array}{l}6.67 \pm 0.67 \\
6.00 \pm 3.06 \\
6.00 \pm 1.15\end{array}$ & $\begin{array}{l}5.81 \pm 2.08 \\
14.1 \pm 1.01 \\
22.4 \pm 2.08\end{array}$ & $\begin{array}{l}0.187 \\
0.361 \\
0.346\end{array}$ & $\begin{array}{l}9.95 \\
39.6 \\
56.0\end{array}$ & $\begin{array}{l}6.24 \\
14.7 \\
22.9\end{array}$ \\
\hline $\begin{array}{l}75-100 \mu \mathrm{m} \\
3.0 \mathrm{mg} \mathrm{MS} / \mathrm{rat} \\
(666 \mu \mathrm{g} \mathrm{IDM} / \mathrm{rat})\end{array}$ & $300 \mathrm{psi}$ & $20.1 \pm 1.73$ & $1.97 \pm 0.16$ & $2.67 \pm 0.67$ & $38.8 \pm 3.75$ & 0.416 & 118 & 14.7 \\
\hline
\end{tabular}

a) $F_{0-24 \mathrm{~h}},\left[\left(A U C_{\text {bombard } 0-24 \mathrm{~h}} /\right.\right.$ Dose $\left.\left.\left._{\text {bombard }}\right) /\left(A U C_{\text {i.c. } 0-24 \mathrm{~h}} / D o s e_{\text {i.c. }}\right)\right] \times 100 . \quad b\right)$ Relationship between the $F_{0-24 \mathrm{~h}}$ and the $\%$ introduction at each particle size range, $20-38 \mu \mathrm{m}$; $r=0.990,44-53 \mu \mathrm{m} ; r=0.952,75-100 \mu \mathrm{m} ; r=0.987$.

obtained at helium pressures of 200 and 300 psi (Table 1). In contrast, the MAR was dependent on the particle size and helium pressure under these conditions. Hence, the absorption rate of IDM (i.e. IDM absorption from the skin to systemic circulation) was found to being determined mainly by the amount of IDM introduced. These results indicate that bombardment with larger microspheres and at higher helium pressures used in this study leads to a more efficient introduction of IDM into the skin, thereby, allowing a higher $F_{0-24 \mathrm{~h}}$ for the IDM systemic availability.

When IDM-loaded PLA MS, $75-100 \mu \mathrm{m}$ in diameter, at different doses were bombarded at a helium pressure of 300 psi, the plasma concentration of IDM increased with increasing bombardment dose (Fig. 1c). The $C_{\max }$ and $A U C_{0-24 \mathrm{~h}}$ values also increased depending on the bombardment dose (Table 1). However, the calculated IDM $F_{0-24 \mathrm{~h}}$ increased on decreasing the bombardment dose, in that a reduction in bombardment dose led to a higher efficiency of systemic absorption from the bombardment site. This is most likely due to a reduction in the particle collisions and in the coefficient of friction between the particles and the walls of the cartridge container after bombardment, thereby, allowing a higher particle velocity to produce a higher introduction and IDM $F_{0-24 \mathrm{~h}}$. In addition, the larger microspheres used at lower doses tended to increase the IDM $F_{0-24 \mathrm{~h}}$, particle size ranges of $75-100 \mu \mathrm{m}$ generally being more efficient than those of $20-38$ and $44-53 \mu \mathrm{m}$ (data not shown). These results indicate that a more efficient IDM $F_{0-24 \mathrm{~h}}$ could be achieved by reducing the bombardment dose as well as the \% introduction obtained. However, it should be noted that the plasma concentration of IDM decreased substantially on reducing the bombardment dose. 
Effects of Discrete Bombardment of IDM-Loaded PLA MS on the Plasma Concentration of IDM In order to improve both the plasma concentration and $F_{0-24 \mathrm{~h}}$ after particle bombardment, IDM-loaded PLA MS, 75-100 $\mu \mathrm{m}$ in diameter, at a dose of $1.0 \mathrm{mg}$ were used to bombard three different sites of the abdomen at a helium pressure of $300 \mathrm{psi}$ to deliver total amounts of $3.0 \mathrm{mg}$ as shown in Fig. 2 and Table 2. When each dose of $1.0 \mathrm{mg}$ IDM-loaded PLA MS was used to bombard three different sites of the abdomen, the plasma concentration of IDM was much higher than that after bombardment with a bolus dose of $3.0 \mathrm{mg}(p<0.01)$. There was no significant difference between the $F_{0-24 \mathrm{~h}}$ values after discrete bombardment of each $1.0 \mathrm{mg}$ dose and bolus bombardment of $1.0 \mathrm{mg}$, suggesting that discrete bombardment at different sites had no effect on the $F_{0-24 \mathrm{~h}}$ values achieved. In contrast, both the $A U C_{0-24 \mathrm{~h}}$ and $F_{0-24 \mathrm{~h}}$ values after discrete bombardment were about 1.5 times higher than those after bombardment with a bolus dose of $3.0 \mathrm{mg}$. Since the \% introduction after bolus bombardment of $1.0 \mathrm{mg}$ was about 2 times higher than that of $3.0 \mathrm{mg}$, the total amounts of IDM introduced after discrete bombardment of each $1.0 \mathrm{mg}$ (dose

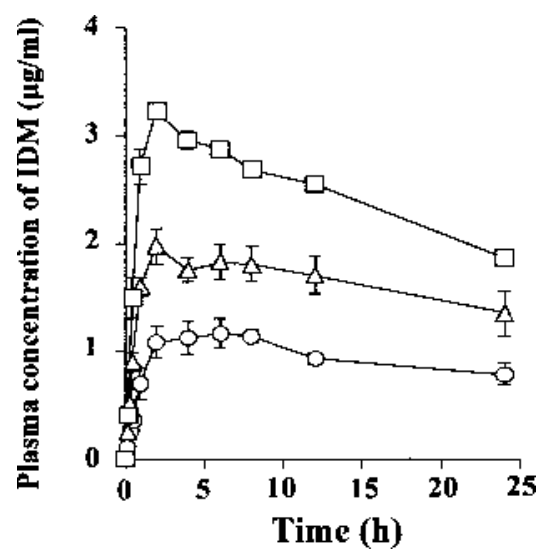

Fig. 2. Plasma Concentration of IDM after Bombardment with IDMLoaded PLA MS Using the Helios ${ }^{\mathrm{TM}}$ Gun System under Various Conditions

Particle size range, $75-100 \mu \mathrm{m}$. Helium pressure, $300 \mathrm{psi}$. Particle bombardment: $\bigcirc, 1.0 \mathrm{mg}$ MS in bolus; $\triangle, 3.0 \mathrm{mg}$ MS in bolus; $\square, 1.0 \mathrm{mg}$ MS $\times 3$ times. Each data point represents the mean and the standard error $(n=3-6)$. equivalent, $3.0 \mathrm{mg}$ ) were higher, thereby, allowing a higher $F_{0-24 \mathrm{~h}}$ and $A U C_{0-24 \mathrm{~h}}$ (i.e. amounts of IDM absorbed). Hence, we found that a more efficient $F_{0-24 \mathrm{~h}}$ was obtained after discrete bombardment at a low dose.

In the present study, we have demonstrated that a successful increase in the plasma IDM concentration is achieved after bombardment of IDM-loaded PLA MS with a larger particle size at a higher helium pressure using the Helios ${ }^{\mathrm{TM}}$ gun system. In particular, a more efficient $F_{0-24 \mathrm{~h}}$ is obtained after discrete bombardment of PLA MS, 75- $100 \mu \mathrm{m}$ in diameter, at a low dose. Thus, a suitable combination of helium pressure and bombardment dose can be used for large microspheres incorporating drugs at different therapeutic doses to provide the desired pharmacological action.

In conclusion, the bombardment injection of drug-loaded microspheres by the Helios ${ }^{\mathrm{TM}}$ gun system has been shown to be a very useful tool for the delivery of a variety of drugs in powder form into the skin and systemic circulation.

Acknowledgements The authors would like to thank Dr. Yi Jin for helpful discussions and useful comments. This work was supported by the Promotional and Mutual Aid Corporation for Private Schools of Japan.

\section{REFERENCES}

1) Bellhouse B. J., Sarphie D. F., Greenford J. C., Intl. Patent Applic., WO 94/24263, 27 October 1994.

2) Sarphie D. F., Johnson B., Cormier M., Burkoth T. L., Bellhouse B. J., J. Control. Release, 47, 61-69 (1997).

3) Burkoth T. L., Bellhouse B. J., Hewson G., Longridge D. J., Muddle A. G., Sarphie D. F., Crit. Rev. Ther. Drug Carrier Syst., 16, 331-384 (1999).

4) Johnson M.-J., Longridge D. J., Hickey P. L., J. Pharm. Pharmacol., 52 (Suppl.), 48 (2000).

5) Chen D., Endres R. L., Erickson C. A., Wels K. F., McGregor M. W., Kawaoka Y., Payne L. G., Nat. Med., 6, 1187-1190 (2000).

6) Chen D., Erickson C. A., Endres R. L., Periwal S. B., Chu Q., Shu C., Maa Y.-F., Payne L. G., Vaccine, 19, 2908-2917 (2001).

7) Uchida M., Jin Y., Natsume H., Kobayashi D., Sugibayashi K., Morimoto Y., J. Pharm. Pharmacol., (accepted).

8) Yamaoka K., Tanigawara Y., Nakagawa T., Uno T., J. PharmacobioDyn., 4, 879-885 (1981).

Table 2. Percentage Introduction and Pharmacokinetic Parameters of IDM after Bombardment with IDM-Loaded PLA MS Using the Helios ${ }^{\mathrm{TM}}$ Gun System under Various Conditions

\begin{tabular}{|c|c|c|c|c|c|}
\hline & $\%$ introduction & $\underset{(\mu \mathrm{g} / \mathrm{ml})}{C_{\max }}$ & $\begin{array}{c}T_{\max } \\
\text { (h) }\end{array}$ & $\begin{array}{l}A U C_{0-24 \mathrm{~h}} \\
(\mu \mathrm{g} \cdot \mathrm{h} / \mathrm{ml})\end{array}$ & $\begin{array}{l}F_{0-24 \mathrm{~h}^{a}} \\
(\%)\end{array}$ \\
\hline $\begin{array}{l}\text { i.c. } \\
(100 \mu \mathrm{g} \text { IDM/kg) }\end{array}$ & - & $1.42 \pm 0.05$ & $0.17 \pm 0.00$ & $10.2 \pm 0.38$ & - \\
\hline $\begin{array}{l}1.0 \mathrm{mg} \text { MS in bolus } \\
(111 \mu \mathrm{g} \mathrm{IDM} / \mathrm{rat})\end{array}$ & $39.6 \pm 3.04$ & $1.21 \pm 0.12$ & $6.00 \pm 1.15$ & $22.4 \pm 2.08$ & 22.9 \\
\hline $\begin{array}{l}3.0 \mathrm{mg} \mathrm{MS} \text { in bolus } \\
(666 \mu \mathrm{g} \mathrm{IDM} / \mathrm{rat})\end{array}$ & $20.1 \pm 1.73$ & $1.97 \pm 0.16$ & $2.67 \pm 0.67$ & $38.8 \pm 3.75$ & 14.7 \\
\hline $\begin{array}{l}1.0 \mathrm{mg} \mathrm{MS} \times 3 \text { times } \\
(666 \mu \mathrm{g} \mathrm{IDM} / \mathrm{rat})\end{array}$ & $38.4 \pm 6.22$ & $3.22 \pm 0.24$ & $2.00 \pm 0.00$ & $58.9 \pm 4.10^{*}$ & 20.1 \\
\hline
\end{tabular}

Particle size range, $75-100 \mu \mathrm{m}$. Helium pressure, 300 psi. a) $F_{0-24 \mathrm{~h}}$, $\left[\left(A U C_{\text {bombard } 0-24 \mathrm{~h}} /\right.\right.$ Dose $\left.\left._{\text {bombard }}\right) /\left(A U C_{\text {ic. } 0-24 \mathrm{~h}} / D o s e_{\text {ic. }}\right)\right] \times 100$. $*$ Significant differences, $p<0.01$ compared with $3.0 \mathrm{mg}$ MS in bolus for $A U C_{0-24 \mathrm{~h}}$. 